\title{
Stability Analysis of Reinforced Slope Based on Limit Equilibrium Method
}

\author{
Fei SONG, Ru-Yi CHEN, Li-Qiu MA, Jian ZHAO
}

\begin{abstract}
Reinforced soil structures are widely used in civil engineering for the slope protection because of their unique advantages. However, the failure mechanism of such structures has not been fully studied. In this paper, the stability analysis of reinforced slopes is carried out based on the limit equilibrium method. Furthermore, the effects of the location, the length and the tensile strength of the reinforcement layers on the safety factor and the critical failure surface are investigated. The research results indicate that the above parameters have great effects on the safety factor and the critical failure surface of the reinforced slope. However, the effects of the length and the tensile strength of the reinforcement on the location where the failure surface starts are not significant. Based on the analysis of computation results, the failure mechanism is analyzed and the optimum design scheme of the reinforced slope is recommended.
\end{abstract}

Keywords: critical failure surface; length; location; reinforced slope; safety factor; tensile strength

\section{INTRODUCTION}

Since Vial [1] in 1969 put forward the concept of reinforced soil, reinforced soil structures have been widely applied in civil engineering in order to increase the stability of embankments and slopes. A lot of researches on the reinforced slope have been done and some valuable achievements have been made. Mandal et al. [2] in 1992 introduced a procedure for the stability analysis and design of geosynthetic reinforced soil slopes. Varadarajan et al. [3] in 1999 investigated the effects of the type of reinforcement, the type of clay, the depth of foundation, and the drainage condition on the behaviour of a reinforced embankment-foundation system by conducting a finite element analysis. Tandjiria et al. [4] in 2002 studied the effect of reinforcement force distribution on the stability of reinforced embankments by using the extended generalized method of slices and made a comparison with results obtained from other analytical or numerical methods. By combining centrifugal model tests and digital image analysis, Zornberg et al. [5] in 2003 studied the strain distribution within geosyntheticreinforced slopes under pre-failure conditions, and analysed the relationship between safety factor and magnitude of the reinforcement maximum peak strain. Teerawattanasuk [6], Bergado and Teerawattanasuk [7] simulated the overall behaviour of the steel grid reinforced "long" embankment and the hexagonal wire mesh reinforced "short" embankment by employing FLAC2D and FLAC3D. Besides, they made a comparison of the numerical simulation results with previous researches. By conducting a series of direct shear tests on sandy soil, Moayedi et al. [8] in 2010 evaluated the effect of optimum reinforcement orientation through the geosynthetic-reinforced slopes. Li et al. [9] in 2012 proposed an approach based on the category of upper bound theorem of limit analysis to consider the reinforcing effect of one row of anchors on slope stabilization. In 2012, Guo et al. [10] studied various influential factors on the reinforced slope stability, such as horizontal peak ground acceleration, slope angle, geological structures, slope height by investigating the dynamic response of a reinforced slope in Wenchuan earthquake in 2008. By using a beam model, Mehdipour et al. [11] in 2013 simulated the geocell behaviour as a flexible slab foundation which can carry both bending and membrane stresses for the stability analysis of geocell reinforced slopes, and discussed the influence of slope geometry, shear strength properties and soil compaction on the behaviour of geocell reinforced slope. Vieira et al. [12] in 2013 analysed the influence of the potential failure surface and geosynthetic strength distribution on the earth pressure coefficient, and computed the required reinforcement tensile strengths based on limit equilibrium analyses.

However, the effects of the location, the length and the tensile strength of reinforcement layers on the stability of the reinforced slope have not been systematically investigated and are still not clear. In this paper, based on the limit equilibrium theory, the stability analysis of the reinforced slope is conducted with the software ZSLOPE developed by Zhang [13] in 2004. Furthermore, the effects of the location, the length and the tensile strength of reinforcement layers on the safety factor and the critical failure surface are investigated and analysed on the basis of the analysis of the calculation results.

\section{MODEL AND PARAMETERS OF CALCULATION}

In the computation and the analysis, the calculation model is composed of the foundation, the embankment and the reinforcement layers, which is illustrated in Fig. 1. In addition, the friction coefficient is set between the reinforcement layers and the backfill, and this is similar to the interface element adopted by Song et al. [14]. The selected calculation parameters of the foundation and the embankment for this study are listed in Tab. 1.

Table 1 Calculation parameters of model
\begin{tabular}{|c|c|c|}
\hline Material & Foundation & Backfill \\
\hline$\gamma /\left(\mathrm{kN} / \mathrm{m}^{3}\right)$ & 18 & 18 \\
\hline$\gamma_{s a t} /\left(\mathrm{kN} / \mathrm{m}^{3}\right)$ & 20 & 20 \\
\hline$c / \mathrm{kPa}$ & 50 & 35 \\
\hline$\varphi /\left({ }^{\circ}\right)$ & 20 & 20 \\
\hline
\end{tabular}

As is shown in Fig. 1, the height of the reinforced slope is $12 \mathrm{~m}$ and the slope ratio is 1:0.25. Twelve reinforcement layers are uniformly placed at the different locations in the slope and the vertical spacing between each is $1 \mathrm{~m}$. The length of the reinforcement layers is $12 \mathrm{~m}$, 
the tensile strength is $80 \mathrm{kN} / \mathrm{m}$, and the inclination angle of the reinforcement force is 0 . Besides, the friction coefficient set between the reinforcement layers and the backfill is 0.9 . In addition, the factor of safety defining a fictitious frictional soil (i.e. a soil with reduced $\varphi$ ) is 1.2. The meaning of the above parameters can be referred to Song et al.[15] in 2016.

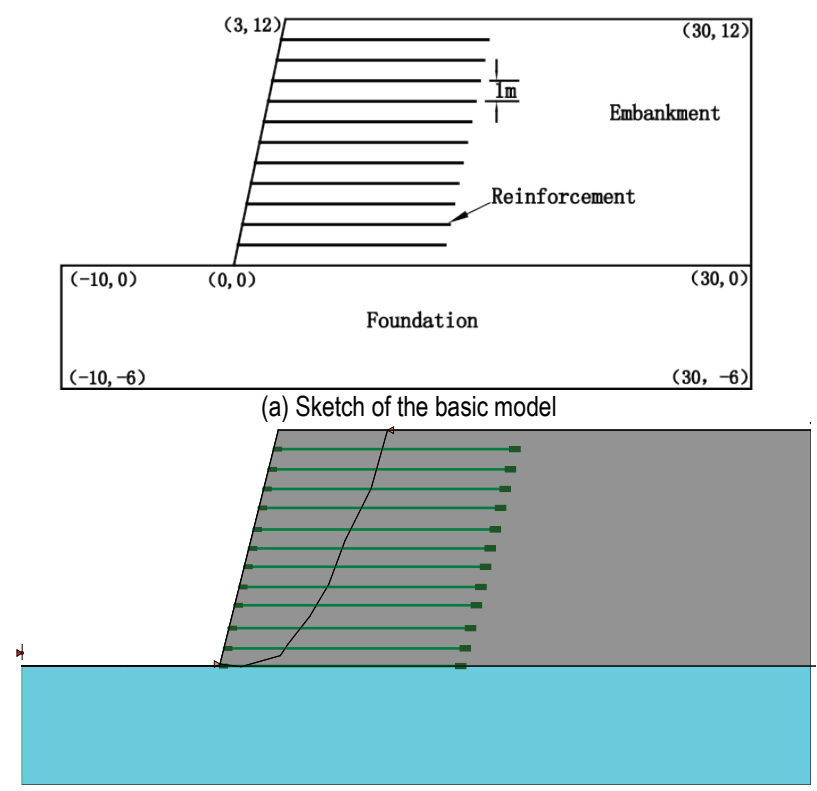

(b) Basic model formulated by the software ZSLOPE Figure 1 Diagram of the basic model (unit: $\mathrm{m}$ )

Other models in the calculation are modified based on the basic model in Fig. 1 in order to study the effects of different parameters. For example, the vertical spacing between the reinforcement layers in certain area is decreased for the study of the effect of location of reinforcement, the lengths of the reinforcement are changed for the study of the effect of the reinforcement length, and the tensile strengths of the reinforcement are modified for the study of the effect of the tensile strength. After the embankment, the foundation and the reinforcement layers are constructed and the mechanical parameters are assigned, the critical failure surface and the safety factor are calculated for different cases. In the calculation, the shape of the failure surface is assumed to be a polygonal line. The method adopted for the calculation of the safety factor of the reinforced slope is the general limit equilibrium (GLE) method, developed by Song et al. [15] in 2016, and that for searching the critical failure surface can be achieved by the improved Monte Carlo techniques proposed by Zhang et al. [16] in 2006.

\section{EFFECT OF LOCATION OF REINFORCEMENT LAYERS}

In order to study the effect of the location of the reinforcement layers, the following three cases are calculated and analysed: The first one, denoted as case a, is reducing the spacing between the reinforcement layers whining the range of 0 to $H / 3$, in which $H$ denotes the height of the slope. The second one, denoted as case $b$, is reducing the spacing between the reinforcement layers whining the range of $H / 3$ to $2 H / 3$. The third one, denoted as case $\mathrm{c}$, is reducing the spacing between the reinforcement layers whining the range of $2 H / 3$ to $H$. In each case, the reduced spacing is $1 / 2$ of that of the basic model. In the computation, the parameters of the reinforcement layers maintain the same value.

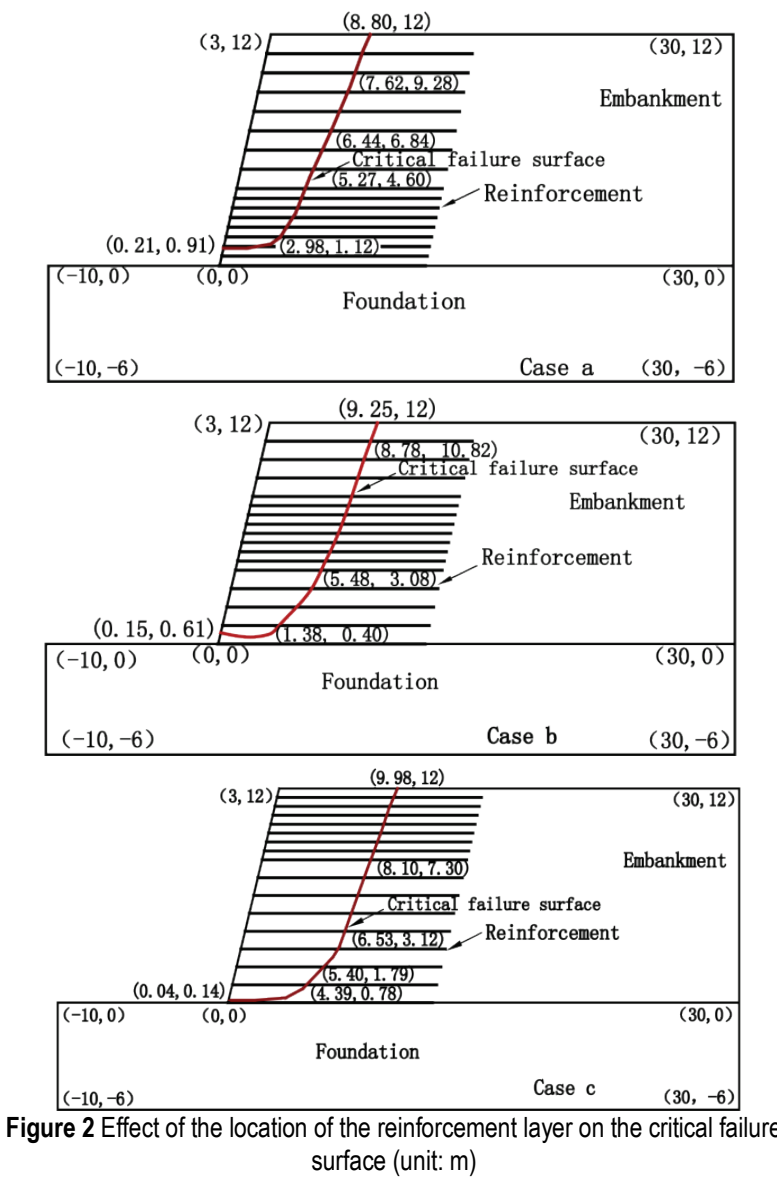

The critical failure surfaces of the reinforced slope in the above three cases are shown in Fig. 2 and comparison of the locations of failure surfaces of them is shown in Fig. 3. It can be seen from Fig. 2 and 3 that the failure surface of the reinforced slope is a curve starting from the area near the slope toe, intersecting with the reinforcement layers and ultimately reaching some place on the top of the slope. Moreover, for the case a, the location of the starting point of the failure surface is relatively high and the distance between the top of the sliding surface and the top of the slope is relatively small, indicating that the size of the sliding wedge is small. However, when the area where the reinforcement layers are at small spacing rises up, the location where the starting point of sliding surface gradually descends and the distance between the top of the sliding surface and the top of the slope gradually increases, resulting in the increase of the size of the sliding wedge. For example, in case $a$, the distance between the starting point of failure surface and the slope bottom is $0.076 \mathrm{H}$. Meanwhile, the distance between the top of the failure surface and the top of the slope is $0.483 H$. However, in case c, the distance between the starting point of the failure surface and the slope bottom is $0.012 \mathrm{H}$. At the same time, the distance between the top of the sliding surface and the top of the slope is $0.582 H$. The above phenomena may be explained as follows. When the spacing between the reinforcement layers within the range of $0-H / 3$ is reduced, the rigidity 
and the strength of the lower area of slope become large and the deformation is small. At the same time, the rigidity and the strength of the upper area remain unchanged and the deformation is relatively large. Therefore, the distance between the starting point of failure surface and the slope bottom becomes large, and the distance between the top of the failure surface and the top of the slope is small, leading to the small size of the sliding wedge. In contrast, when the spacing between the reinforcement layers within the range of $2 H / 3-H$ is reduced, the rigidity and the strength of the upper area of the slope becomes large and the deformation is small. At the same time, the rigidity of the lower area remains unchanged and the deformation is relatively large. Therefore, the distance between the starting point of failure surface and the slope bottom becomes small, and the distance between the top of the sliding surface and the top of the slope is large, leading to the large size of the sliding wedge.

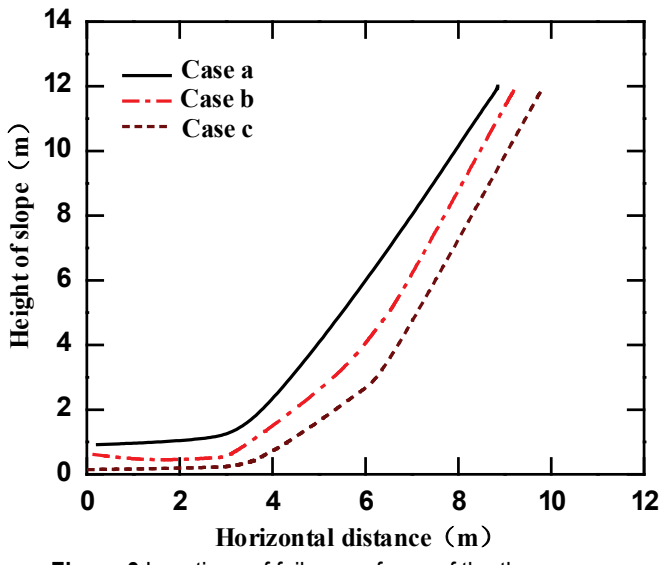

Figure 3 Locations of failure surfaces of the three cases

The safety factors of the reinforced slope of the basic model and the above three cases are also calculated by the software ZSLOPE and illustrated in Tab. 2. It can be observed from Table 2 that the safety factor of the basic model is the smallest. When the vertical spacing of the reinforcement layers within the range of $0-H / 3$ is reduced, the safety factor of the reinforced slope is the highest. However, it gradually decreases when the area of reinforcement layers with small spacing goes up. Therefore, in engineering practices, it is recommended that the reinforcement layers with small spacing should be placed in the lower area of the slope, so that the safety factor is relatively high.

Table 2 Safety Factor of the four cases

\begin{tabular}{|c|c|}
\hline Models & Safety factor \\
\hline Basic model & 0.983 \\
\hline Case a & 1.630 \\
\hline Case b & 1.196 \\
\hline Case c & 1.090 \\
\hline
\end{tabular}

\section{EFFECT OF THE LENGTH OF THE REINFORCEMENT LAYERS}

The effect of the length of the reinforcement layers on the location of the critical failure surface and the safety factor is analysed by employing the software ZSLOPE. In the computation, only the value of $l$, which represents the length of the reinforcement layers, is changed, and other parameters remain the same value with those of the basic model shown in Tab. 1 . The cases of $l=12 \mathrm{~m}, 15 \mathrm{~m}, 18 \mathrm{~m}$, $21 \mathrm{~m}$, and $24 \mathrm{~m}$ are calculated and analysed. The location of the failure surfaces of the reinforced slope when $l=12$ $\mathrm{m}, 15 \mathrm{~m}$, and $18 \mathrm{~m}$ are provided in Fig. 4. Furthermore, the comparison of the failure surfaces of the reinforced slope with $l=12 \mathrm{~m}, 15 \mathrm{~m}, 18 \mathrm{~m}, 21 \mathrm{~m}$, and $24 \mathrm{~m}$ is shown in Fig. 5.
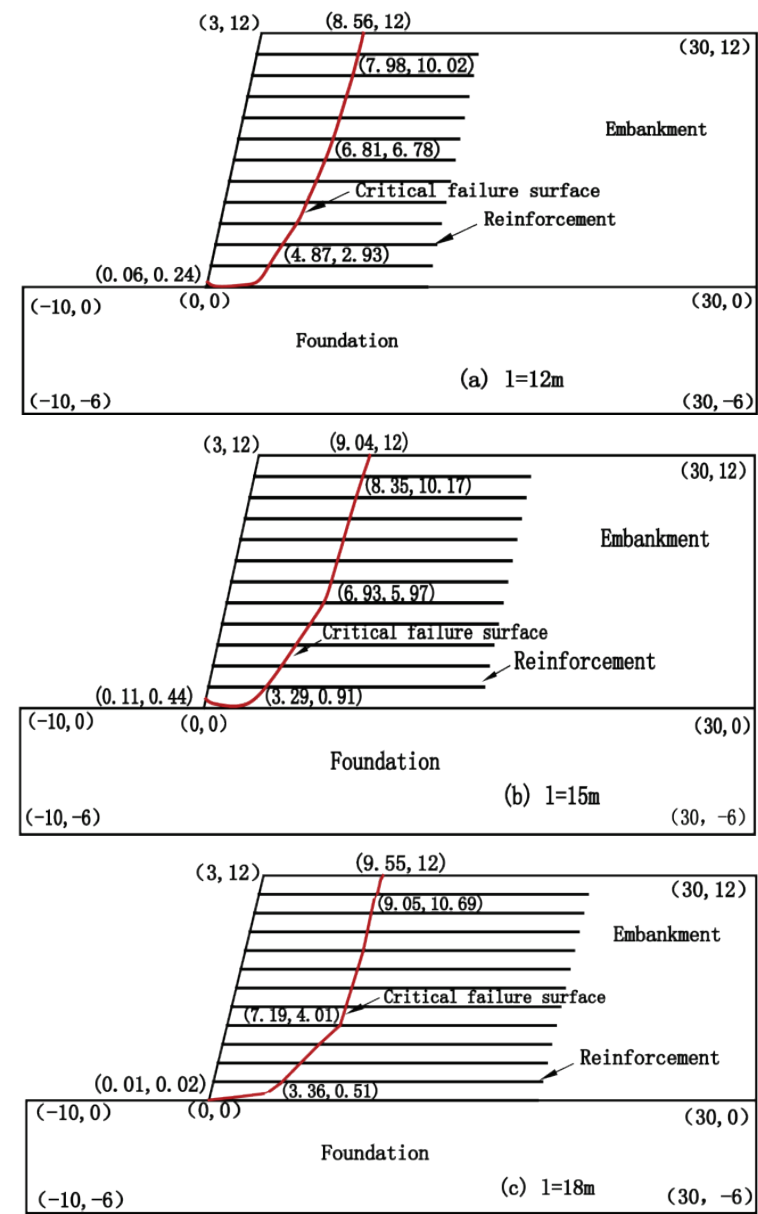

Figure 4 Effect of the length of the reinforcement layers on the failure surface (unit: $m$ )

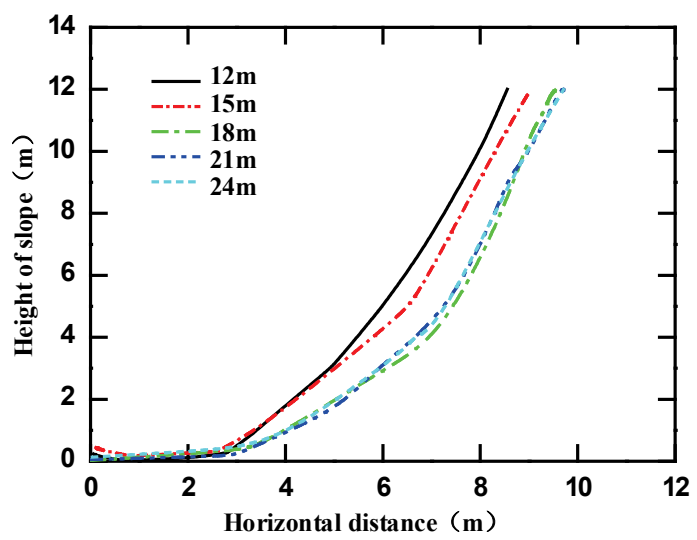

Figure 5 Locations of failure surface of reinforced slope with different $l$ values

It can be seen from Fig. 4 and 5 that when the length of the reinforcement layers of the reinforced slope is small, the distance between the top of the failure surface and the top of the slope is small. However, it gradually increases with the increase of the reinforcement length, resulting in 
the increase of the size of the sliding wedge. In comparison with the effect of the location of the reinforcement layers, the effect of the length of the reinforcement layers on the location where the failure surface starts is not obvious. For example, for the case of $l=12 \mathrm{~m}$, the distance between the top of the sliding surface and the top of the slope is $0.463 H$. When $l=18 \mathrm{~m}$, the distance between the top of the sliding surface and the edge of the surface on the top of the slope is $0.546 H$. Nevertheless, when the length of the reinforcement layers continues to increase, the location of the failure surface maintains almost the same when $l \geq 18 \mathrm{~m}$. The above phenomena may be explained as follows. When the value of $l$ is small, the rigidity and the strength of the whole reinforced slope are small and the deformation is large. Therefore, the instability zone is small, resulting in the small sliding soil wedge. It is consistent with the previous studies of Song et al. (2014) [17]. On the contrary, when the value of $l$ becomes large, the rigidity and the strength of the whole reinforced slope are large and the deformation is small. Therefore, the instability zone becomes large, resulting in the large sliding wedge. Furthermore, when the length of the reinforcement layers increases to a certain degree, the rigidity and the strength of the whole reinforced slope may no longer increase, hence the failure surface does not change any more.

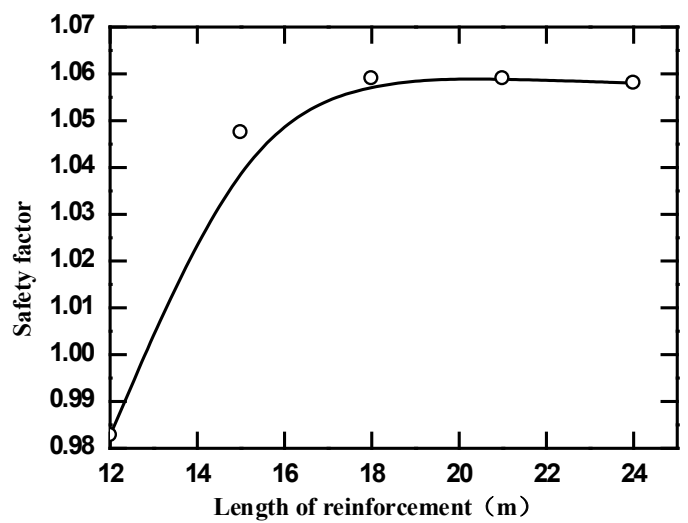

Figure 6 Safety factors of the reinforced slope with different $l$ values

Safety factors of the reinforced slopes with $l=12 \mathrm{~m}, 15$ $\mathrm{m}, 18 \mathrm{~m}, 21 \mathrm{~m}$, and $24 \mathrm{~m}$ are computed by the software ZSLOPE and illustrated in Fig. 6. It can be seen from Fig. 6 that the safety factor of the reinforced slope is small with small $l$ values, and it gradually increases with the increase of the value of $l$. However, the safety factor maintains nearly the same value when the value of $l$ is larger than $18 \mathrm{~m}$. This is because when the value of $l$ is small, the embedded length beyond the critical failure surface is small and the pull-out resistance provided by the reinforcement is also small, leading to a small safety factor. With the increase of the length of the reinforcement, the embedded length beyond the critical failure surface becomes large, resulting in the greater pull-out resistance provided by the reinforcement. This is probably because the reinforced area in the soil mass becomes large with the increase of the reinforcement length. However, when $l \geq 1.5 H$, the pull-out resistance equals or becomes greater than the tensile strength of the reinforcement, at this time, the anti-sliding forces supplied by the reinforcement no longer increase.
Therefore, the safety factor and the critical failure surface do not change anymore.

\section{EFFECT OF THE TENSILE STRENGTH OF THE REINFORCEMENT LAYERS}

In order to increase the stability of the reinforced slope, reinforcement with high tensile strength is employed in engineering practices. The effect of the reinforcement strength on the failure mode of the slope is also investigated in this paper. In the computation, only the value of $t$, which represents the tensile strength of the reinforcement layers, is changed, and other parameters are consistent with the basic model shown in Fig. 1. The cases of $t=80 \mathrm{kN} / \mathrm{m}, 120 \mathrm{kN} / \mathrm{m}, 160 \mathrm{kN} / \mathrm{m}, 200 \mathrm{kN} / \mathrm{m}$, and $240 \mathrm{kN} / \mathrm{m}$ are calculated and analysed. The location of the critical failure surfaces of the reinforced slopes with $t=80$ $\mathrm{kN} / \mathrm{m}, 160 \mathrm{kN} / \mathrm{m}$, and $240 \mathrm{kN} / \mathrm{m}$ are provided in Fig. 7 . Furthermore, the comparison of critical failure surfaces with $t=80 \mathrm{kN} / \mathrm{m}, 120 \mathrm{kN} / \mathrm{m}, 160 \mathrm{kN} / \mathrm{m}, 200 \mathrm{kN} / \mathrm{m}$, and $240 \mathrm{kN} / \mathrm{m}$ is illustrated in Fig. 8.
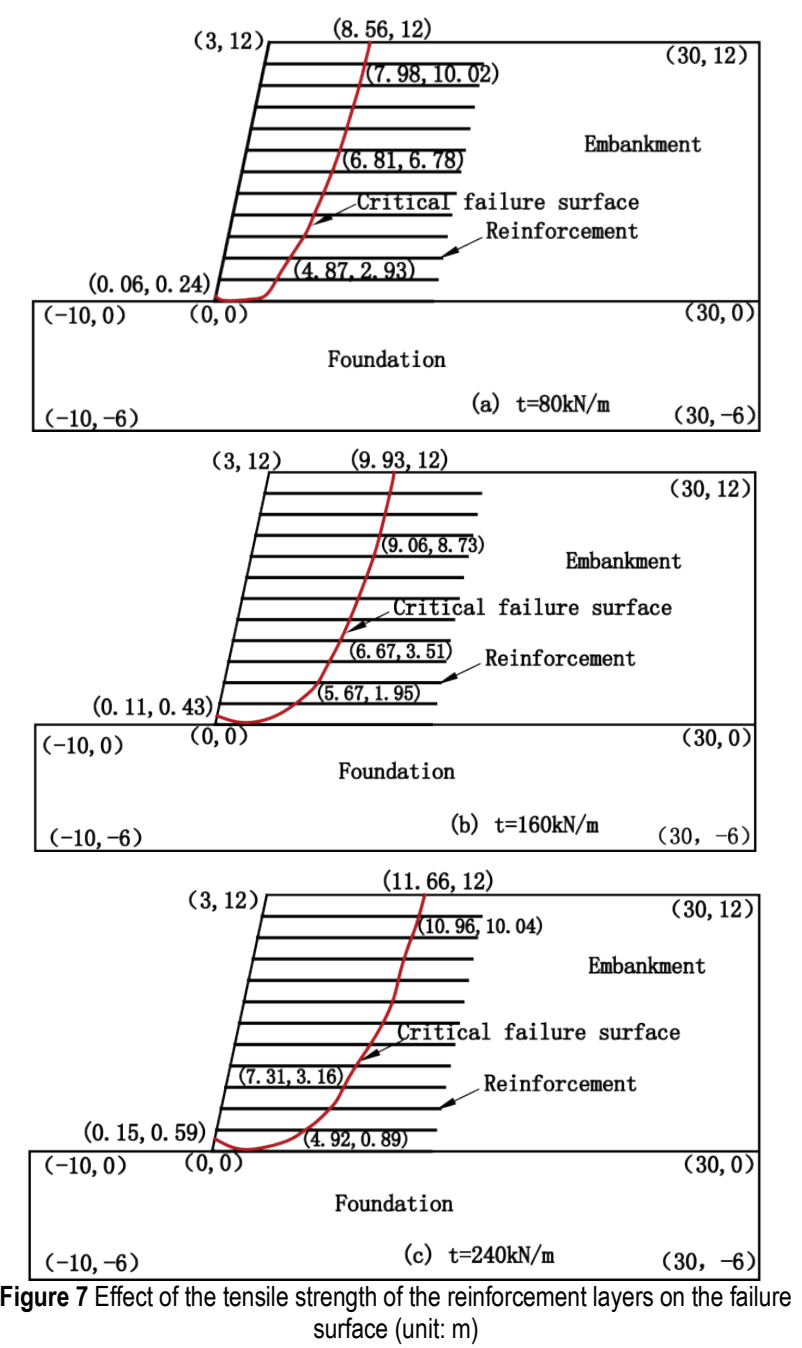

It can be seen from Fig. 7 and 8 that the range of sliding soil mass gradually increases with the increase of the reinforcement tensile strength. This is because the rigidity and the strength of the reinforced slope increase with the increase of reinforcement tensile strength, resulting in the reduction of the deformation of the reinforced slope. The distance between the top of the 
sliding surface and the top of the slope enlarges with the increase of the reinforcement tensile strength. However, the location where the failure surface starts is not significantly affected by the change of the $t$ value.

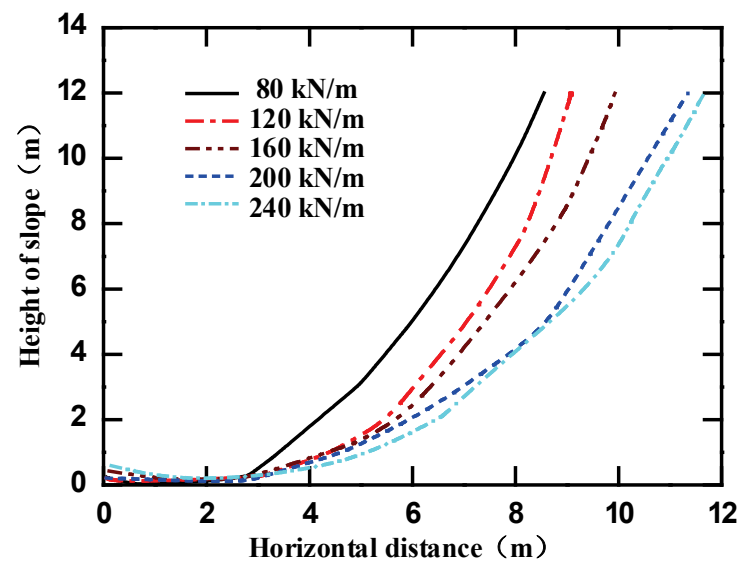

Figure 8 Locations of failure surface of reinforced slope with different $t$ values

The effect of the reinforcement tensile strength on the safety factor is also computed and shown in Fig. 9, from which it can be observed that the safety factor increases with the reinforcement tensile strength.

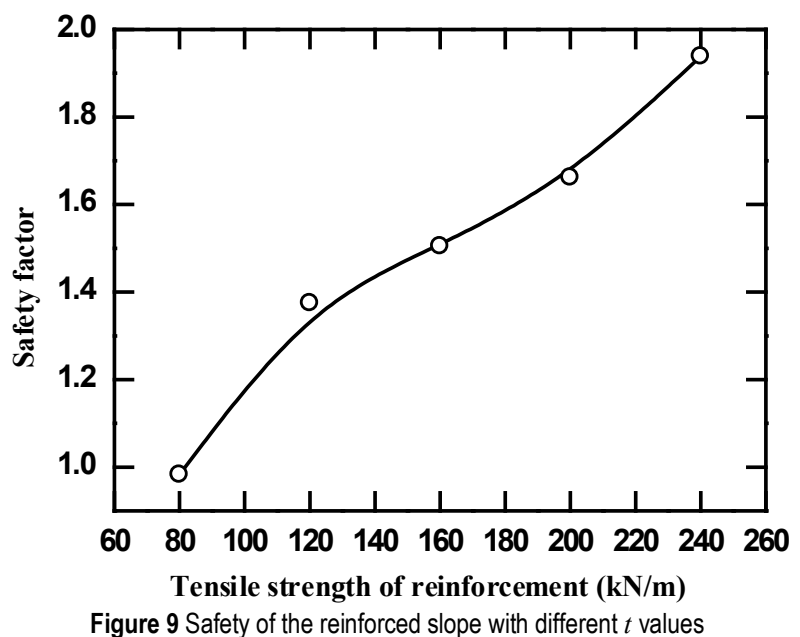

\section{CONCLUSIONS}

In this paper, the effects of the location, the length and the tensile strength of reinforcement layers on the critical failure surface and the safety factor of the reinforced slopes are investigated by the limit equilibrium analysis. The following conclusions can be primarily drawn on the basis of the analysis of the calculation results:

(1) The location of the reinforcement layers has an important effect on the critical failure surface and the safety factor of the reinforced slope. When the vertical spacing between the reinforcement layers within the range of $0-H / 3$ is reduced, the size of the sliding soil wedge is relatively small, and the safety factor is large. However, with the area of reinforcement layers with small spacing going up, the location where the sliding surface starts gradually descends, the distance between the top of the failure surface and the top of the slope gradually increases, resulting in the enlarging of the size of the sliding soil wedge. At the same time, the safety factor decreases.

(2) The length of the reinforcement layers of the reinforcement slope has a significant effect on the critical failure surface and the safety factor of reinforced slope. When the length of the reinforcement layers of the reinforced slope is small, the size of the sliding soil wedge and the safety factor are relatively small. With the increase of the length of the reinforcement layers, the size of the sliding soil wedge and the safety factor gradually increase. However, when the length of the reinforcement layers increases to the value larger than $1.5 \mathrm{H}$, the failure surface does not change any more and the safety factor maintains a constant. The effect of the length of the reinforcement layers on the location where the failure surface starts is not significant.

(3) When the tensile strength of the reinforcement is small, the size of sliding soil wedge and the safety factor of the slope are both small. With the increase of the tensile strength of the reinforcement, the size of the sliding soil wedge and the safety factor gradually increase. However, the effect of the tensile strength of the reinforcement on the location where the failure surface starts is not obvious.

\section{Acknowledgements}

The authors wish to express their sincere gratitude to the Scientific Project funded by the Ministry of Housing and Urban-Rural Development of the People's Republic of China Council (No. 2015-K2-008).

\section{REFERENCES}

[1] Vidal, H. (1969). The principle of reinforced earth. Highway Res. Rec. 282, 1-16.

[2] Mandal, J. N. \& Labhane, L. (1992). A procedure for the design and analysis of geosynthetic reinforced soil slopes. Geotechnical and Geological Engineering, 10, 291-319. https://doi.org/10.1007/BF00880706

[3] Varadarajan, A., Sharma, K. G. \& Aly, M. A. A. (1999). Finite element analysis of reinforced embankment foundation. International Journal for Numerical and Analytical Methods in Geomechanics, 23, 103-114. https://doi.org/10.1002/(SICI)1096-9853(199902)23:2<103::AIDNAG959>3.0.CO;2-V

[4] Tandjiria, V., Low, B. K. \& Teh, C. I. (2002). Effect of reinforcement force distribution on stability of embankments. Geotextiles and Geomembranes, 20(6), 423443. https://doi.org/10.1016/S0266-1144(02)00015-8

[5] Zornberg, J. G. \& Arriaga, F. (2003). Strain distribution within geosynthetic-reinforced slopes. Journal of Geotechnical and Geoenvironmental Engineering, 10, 3245. https://doi.org/10.1061/(ASCE)1090-0241(2003)129:1(32)

[6] Teerawattanasuk, C. (2004). Modeling of hexagonal wire reinforcement and 2D/3D simulation of full scale embankment. Doctoral Dissertation GE-03-03, Asian Institute of Technology, Bangkok, Thailand.

[7] Bergado, D. T. \& Teerawattanasuk, C. (2008). 2D and 3D numerical simulations of reinforced embankments on soft ground. Geotextiles and Geomembranes, 26(1), 39-55. https://doi.org/10.1016/j.geotexmem.2007.03.003

[8] Moayedi, H., Huat, B. B. K., Kazemian, S. \& Asadi, A. (2010). Optimization of tension absorption of geosynthetics through reinforced slope. Electronic Journal of Geotechnical Engineering, 15, 93-104. 
[9] Li, X. P., He, S. M. \& Wu, Y. (2012). Limit analysis of the stability of slopes reinforced with anchors. International Journal for Numerical and Analytical Methods in Geomechanics. 36(17), 1898-1908.

https://doi.org/10.1002/nag.1093

[10] Guo, D. P. \& Hamada, M. (2012). Observed stability of natural and reinforced slopes during the 2008 Wenchuan earthquake. Journal of Japan Society of Civil Engineers, 2, 481-494.

[11] Mehdipour, I., Ghazavi, M. \& Moayed, R. Z. (2013) Numerical study on stability analysis of geocell reinforced slopes by considering the bending effect. Geotextiles and Geomembranes, 37, 23-34.

https://doi.org/10.1016/j.geotexmem.2013.01.001

[12] Vieira, C. S., Lopes, M. L. \& Caldeira, L. M. (2013). Limit equilibrium analyses for internal design of geosynthetic reinforced slopes: influence of potential failure surface and strength distribution. GeotechGeol Eng., 31(4), 1123-1135. https://doi.org/10.1007/s10706-013-9639-1

[13] Zhang, L. Y. (2004). Development of software ZSLOPE for slope stability analysis. Chinese Journal of Rock Mechanics and Engineering, 23(16), 2830-2835.

[14] Song, F., Cao, G. R., Zhang, L. Y. \& Tan, X. M. (2013). Numerical analysis of failure mode of geocell flexible retaining wall. ASCE Geotechnical Special Publication, 232, 136-145. https://doi.org/10.1061/9780784413128.017

[15] Song, F., Chen, R. Y., Ma, L. Q. \& Cao, G. R. (2016). A New Method for the Stability Analysis of GeosyntheticReinforced Slopes. Journal of Mountain Science, 13(10), 2069-2078. https://doi.org/10.1007/s11629-016-4001-8

[16] Zhang, L. Y. \& Zhang, J. M. (2006). The extended Monte Carlo techniques by rotating slip segments for searching general critical slip surface $(\alpha)$ : Constant angle of rotation. Rock and Soil Mechanics, 27(12), 2197-2202.

[17] Song, F., Chen, H., Xiao, B. \& Zhang, L. Y. (2014) Investigation on the optimum section form of geocell reinforced two-stage retaining wall. International Journal of Earth Sciences and Engineering, 4, 1376-1382.

Contact information:

Fei SONG, Associate professor

Corresponding author

Institute of Geotechnical Engineering,

School of Highway Engineering,

Chang'An University

Xi'an, 710064, P.R. China

E-mail: songf1980@163.com

\section{Ru-Yi CHEN, Postgraduate}

Institute of Geotechnical Engineering,

School of Highway Engineering,

Chang'An University

Xi'an, 710064, P.R. China

E-mail: cry_947522468@163.com

Li-Qiu MA, Senior Engineer

Guizhou Electricity Engineering Construction Supervise Company

Guiyang, 550005, P.R. China

E-mail: Iqmo_912@163.com

Jian ZHAO, Senior Engineer

Guizhou Electric Power Design and Research Institute

Chongaing, 400067, P. R. China

E-mail: 23498742@qq.com 